\title{
First Steps in the Formulation of Praziquantel Nanosuspensions for Pharmaceutical Applications
}

Noelia A. Martínez, Fátima Fernández-Álvarez, Ángel V. Delgado, María Luisa Badillo-García, Julio Raba, Soledad E. Cerutti \& José L. Arias

To cite this article: Noelia A. Martínez, Fátima Fernández-Álvarez, Ángel V. Delgado, María Luisa Badillo-García, Julio Raba, Soledad E. Cerutti \& José L. Arias (2020): First Steps in the Formulation of Praziquantel Nanosuspensions for Pharmaceutical Applications, Pharmaceutical Development and Technology, DOI: 10.1080/10837450.2020.1756320

To link to this article: https://doi.org/10.1080/10837450.2020.1756320

Accepted author version posted online: 23

Apr 2020.

Submit your article to this journal $₫$

Q View related articles $๘$

View Crossmark data ¿ 


\section{First Steps in the Formulation of Praziquantel}

\section{Nanosuspensions for Pharmaceutical Applications}

Noelia A. Martínez, ${ }^{1,2}$, Fátima Fernández-Álvarez ${ }^{3}$, Ángel V. Delgado ${ }^{4}$, María Luisa Badillo-

García ${ }^{3}$, Julio Raba ${ }^{2}$, Soledad E. Cerutti², José L. Arias ${ }^{3,5,6, *}$

${ }^{1}$ Department of Pharmacy, Faculty of Chemistry, Biochemistry, and Pharmacy, National University of San Luis, Argentina.

${ }^{2}$ Institute of Chemistry of San Luis (INQUISAL), National Council of Scientific and Technical Investigations (CONICET), National University of San Luis, Argentina.

${ }^{3}$ Department of Pharmacy and Pharmaceutical Technology, Faculty of Pharmacy, University of Granada, Spain.

${ }^{4}$ Department of Applied Physics, Faculty of Sciences, University of Granada, Spain.

${ }^{5}$ Institute of Biopathology and Regenerative Medicine (IBIMER), University of Granada, Spain.

${ }^{6}$ Biosanitary Institute of Granada (ibs.GRANADA), Andalusian Health Service (SAS) - University of Granada, Spain.

*Corresponding author.

\section{Mailing address:}

Dr. José L. Arias

Departamento de Farmacia y Tecnología Farmacéutica, Facultad de Farmacia, Universidad de Granada, 18071 - Granada, España.

Phone: (+34) 958243900

Fax: (+34) 958248958

e-mail: jlarias@ugr.es 


\begin{abstract}
Praziquantel, a broad spectrum anthelmintic drug, cannot be found in acceptable dosage forms for elderly patients, paediatric patients, and for veterinary use. In fact, very little has been done up to now in the formulation of liquid dosage forms, being they always formulated for parenteral administration. To beat this important challenge, it was accomplished a comprehensive analysis of the influence of two elementary physicochemical aspects, i.e. surface thermodynamic and electrokinetic properties, on the colloidal stability of praziquantel nanosuspensions. The hydrophobic character of the drug, intensely determining the flocculation curves, was confirmed by the thermodynamic characterization. The electrophoretic characterization, in combination with the sedimentation and relative absorbance versus time curves, highlighted that the electrical double layer thickness and the surface charge can play an essential role in the stability of the pharmaceutical colloid. Finally, it was demonstrated that controlling the $\mathrm{pH}$ values and the incorporation of electrolytes can help in formulating praziquantel aqueous nanosuspensions with appropriate stability and redispersibility behaviours for pharmaceutical use.
\end{abstract}

Keywords: correlation zeta potential - sedimentation; electrophoresis; human and veterinary liquid dosage forms; paediatric drug formulations; praziquantel; surface thermodynamics. 


\section{Introduction}

Helminths are parasitic worms characterized by a bilateral symmetry and by an elongated, flat, or round morphology. Depending on the specie, the size of these invertebrates varies from millimeters to meters. In the group, nematodes include soil-transmitted helminthes or the so-called intestinal worms commonly responsible for helminthiasis, and filarial worms that are described to cause lymphatic filariasis and onchocerciasis. With respect to platyhelminths, trematodes or flukes (i.e. schistosomes) and cestodes or tapeworms are frequently defined to be responsible for parasitic infections in humans and animals (Hotez et al., 2008; Hotez and Aksoy, 2017). Helminth infestation causes morbidity and mortality, affecting cognitive processes, compromising the nutritional status, inducing tissue reactions and causing intestinal obstruction or rectal prolapse. Preschool children and school-aged children, including adolescents, are commonly infected by intestinal worms and schistosomes, experiencing stunted growth and cognitive and memory impairments (resulting in cognitive and educational deficits) (Crompton and Nesheim, 2002; Hotez and Aksoy, 2017).

The neglected tropical disease Bilharzia, or schistosomiasis, is an acute and chronic parasitic infection that can result in serious damage to internal organs. It is caused by trematodes belonging to the genus Schistosoma, principally by Schistosoma mansoni, S. japonicum, and S. haematobium (Lustigman et al., 2012; Raso et al., 2007). The disease is a significant public health issue with severe socio-economic impacts in developing countries (King et al., 2005; Steinmann et al., 2006). The acute phase of the disease is generally asymptomatic, but fever, cough, diarrhoea, a red and itchy rash, and joint and abdominal pains are usually described (Olveda et al., 2013; Ross et al., 2013). On the opposite, acute local inflammatory lesions are reported in chronic schistosomiasis to be produced by the remaining trematode eggs trapped in tissues, while massive infestations are characterized by pseudopolyps in bladder and intestinal light (Colley et al., 2014).

Praziquantel (PZQ) is a broad spectrum and very effective anthelmintic drug being not only used in the treatment of schistosomiasis, but also in the prevention and early treatment of schistosomal infections. In fact, this is the chemotherapy agent of choice for an efficient treatment 
in all species of Schistosoma (Caffrey, 2007), and it is included in the World Health Organization (WHO) Model List of Essential Medicines for Children (Hoppu and Sri Ranganathan, 2015). Additionally, PZQ is a highly lipophilic agent characterized by a low aqueous solubility and a high permeability, which is thus classified as a Class II drug according to the Biopharmaceutics Classification System (BCS) (Linderberg et al., 2004). The hydrophobic character of the compound has limited the development of acceptable (i.e. liquid) dosage forms for elderly patients, paediatric patients, and for veterinary use. Indeed, the common marketed formulations of PZQ are oral solid dosage forms (e.g. tablets) that frequently are improper to those groups of patients and for a flexible drug dosing (Conway et al., 2013). Regarding the formulation of liquid PZQ dosage forms, little has been performed heretofore: the active agent is only described in oily suspensions (Qian et al., 2017; Tang et al., 2016), or loaded to liposomes (Mourão et al., 2005) and nanoparticulate systems, e.g. solid lipid nanoparticles (Xie et al., 2011), poly(methyl methacrylate) nanoparticles (Malhado et al., 2016), and chitosan nanoparticles (Torabi et al., 2018), being they always formulated for parenteral administration.

The present contribution has been devoted to the definition of a basic aspect in the formulation of PZQ nanosuspensions as oral liquid dosage forms for human and veterinary use, i.e. the control and prediction of the stability and redispersibility properties of the colloid. Given their relevance to these characteristics (Arias et al., 2009; Gallardo et al., 2000, 2003), the surface thermodynamics (hydrophilic/hydrophobic nature) and the electrical properties of the drug/liquid interface were analysed, additionally evaluating the effects of both $\mathrm{pH}$ and electrolyte content of the dispersion medium. 


\section{Materials and methods}

\subsection{Materials}

Chemicals were of analytical quality from Panreac Química S.A.U. (Spain), except for PZQ (Guinama S.L.U., Spain; complying the European Pharmacopoeia requirements), formamide (Carlo Erba, Italy) and diiodomethane (Merck KGaA, Germany). Water used was previously deionized and filtered (Milli-Q Academic System, Millipore, Spain).

\subsection{Methods}

\subsubsection{Preparation of the PZQ aqueous nanosuspensions}

Aqueous nanodispersions of the anthelmintic drug $(0.5 \%, \mathrm{w} / \mathrm{v})$ were obtained by progressive incorporation of the solid to water under sonication. Prior to the addition of PZQ, the microtip of the sonicator was immersed in the aqueous phase, leaving one $\mathrm{cm}$ distance from the bottom of the flask without touching its walls. Pulsed mode, with a cycle of 50\%, was used because it facilitated a better temperature control than continuous mode operation, and avoided a temperature increase in the dispersion. For further temperature control, flasks were surrounded with ice during the process.

An alternative procedure, that could be easily scalable at the industrial scale, consisted in the dropwise addition of the drug particles, under mechanical stirring $(3,000 \mathrm{rpm})$ to the aqueous dispersion medium. In accordance to the sonication method, it also assured the generation of homogeneous PZQ nanosuspensions.

\subsubsection{Size of the PZQ particles}

Mean hydrodynamic diameters (and polydispersity index, PdI) of the anthelmintic particles were determined by dynamic light scattering (Zetasizer Nano ZS, Malvern Instruments Ltd., UK) ( $n$ $=12)$. The scattering angle was set at $90^{\circ}$, and the measurements of the aqueous dispersions $(\approx$ $0.1 \%, \mathrm{w} / \mathrm{v})$ were done after equilibration during $2 \mathrm{~min}$ to $25.0 \pm 0.5^{\circ} \mathrm{C}$. 
The technique was further used to evaluate the evolution with time (up to six months) of the particle size in nanosuspensions stored under standard conditions $\left(4.0 \pm 0.5^{\circ} \mathrm{C}\right)$.

\subsubsection{Hydrophobic/hydrophilic character}

To define the wettability (hydrophobic / hydrophilic character) of PZQ particles, it was used a surface thermodynamic model capable of evaluating the surface-free energy components of the solid, $\gamma_{s}$ (Adamson and Gast, 1997; van Oss, 2006). This is a well-known model that has clearly demonstrated its suitability in colloids and suspensions formulated for pharmaceutical applications (Arias et al. 2008, 2009; Cózar-Bernal et al., 2010; Viota et al., 2010). Measurements of the contact angle $(\theta)$ of three liquids (water, formamide, and diiodomethane) on pellets of powdered PZQ solids (diameter $\approx 1 \mathrm{~cm}$ ) were done at $25.0 \pm 0.5^{\circ} \mathrm{C}$, using a goniometer (model 100/07/00, Ramé-Hart, Inc., USA) equipped with a charge-coupled device (CCD) camera and a digital image analysis of drop pictures. Pellets were prepared by compressing the dry powder in a hydraulic press (Specac ${ }^{\mathrm{TM}}$, UK) set to 2 Ton during 5 min.

\subsubsection{Stability of the aqueous nanosuspensions}

Complementarily to the electrophoretic study (see Section 2.2.5.), two methods were used to characterize the stability of PZQ nanosuspensions $(0.5 \%, w / v)$. The first one consisted in the measurement of the sediment volume, $V_{\mathrm{s}}$, after keeping these dispersions in $0.1 \mathrm{~L}$ cylinders (inner radius $\approx 1.2 \mathrm{~cm})$ at $25.0 \pm 0.5{ }^{\circ} \mathrm{C}$. The flocculation ratio $(F \%)$ was then calculated as $V_{\mathrm{s}} / V_{0}(\%)$, where $V_{0}$ is the initial volume of the suspension (Matthews and Rhodes, 1970).

The second method, suitable for dilute pharmaceutical dispersions (Arias et al. 2009; CózarBernal et al., 2010), was based on the measurement as a function of time of the optical absorbance (A) of drug nanosuspensions $(\lambda=500 \mathrm{~nm}$; PerkinElmer UV/Vis Lambda 25 spectrophotometer, PerkinElmer, USA) at room temperature. 
Finally, redispersibility of the PZQ sediments was evaluated by visual inspection of the nanosuspensions after placing them in an ultrasonic bath (model Branson 5200E4, Branson, USA; set at $40 \mathrm{kHz}$, with a sonic power of 100W) (Arias et al. 2009; Cózar-Bernal et al., 2010). Results were found to be equal to moderate hand shaking of the suspensions $(\approx 3 \mathrm{~min})$.

\subsubsection{Surface electrical properties of $P Z Q$ particles}

The electrophoretic properties of the FBZ colloids $(\approx 0.05 \%$, w/v) were analysed (Zetasizer Nano ZS device) as a function of both electrolyte concentration (ionic strength), i,e. $\mathrm{NaCl}$, $\mathrm{CaCl}_{2} \cdot 4 \mathrm{H}_{2} \mathrm{O}$, or $\mathrm{AlCl}_{3} \cdot 6 \mathrm{H}_{2} \mathrm{O}$ (concentrations from $0.01 \mathrm{mM}$ to $0.1 \mathrm{M}$ ), and $\mathrm{pH}$ (adjusted with either $\mathrm{NaOH}$ or $\mathrm{HCl})$. These well-known electrolytes $\left(\mathrm{NaCl}, \mathrm{CaCl}_{2}\right.$, and $\left.\mathrm{AlCl}_{3}\right)$ are classically used to stabilize aqueous pharmaceutical suspensions (Abrahamsson and Odman, 2008; Arias et al., 2008, 2009; Cózar-Bernal et al., 2010; Gallardo et al., 2003). $\mathrm{NaCl}$ and $\mathrm{CaCl}_{2}$ were approved by the Food and Drug Administration (F.D.A.) and, despite $\mathrm{AlCl}_{3}$ has not been yet approved by this Administration, it was included in the study to fully analyse the effect of the type of electrolyte and its concentration on the stability of PZQ suspensions. Measurements were done after $24 \mathrm{~h}$ of contact at room temperature under mechanical stirring $(100 \mathrm{rpm})$, and after 2 min equilibration time at 25.0 $\pm 0.5^{\circ} \mathrm{C}$. The experimental uncertainty of the measurements was $<3 \%$.

\section{Results and discussion}

\subsection{Size and surface thermodynamics of $P Z Q$ particles}

PZQ particles were found to be of colloidal size and moderately monodisperse. The average diameter ( \pm standard deviation) and polydispersity index were $610 \pm 70 \mathrm{~nm}$ and 0.089 , respectively.

Regarding the wettability of the anthelmintic drug, it is important to define this behaviour in aqueous media when preparing a nanosuspension. With that aim, the evaluation of the surface thermodynamics of drug particles has demonstrated to be of great help, especially when considering the data coming from the non-polar Lifshitz-van der Waals $\left(\gamma_{s}^{L W}\right)$, the electron-donor $\left(\gamma_{s}^{-}\right)$, and the 
electron-acceptor $\left(\gamma_{s}^{+}\right)$components to elucidate the nature of a pharmaceutical solid (Adamson and Gast, 1997; Arias et al. 2008; Cózar-Bernal et al., 2010). This study started with the quantification of the contact angles $(\theta)$ of water, formamide, and diiodomethane on dry PZQ pellets: $83^{\circ} \pm 2^{\circ}, 53^{\circ}$ $\pm 1^{\circ}$, and $20^{\circ} \pm 2^{\circ}$, respectively.

The $\theta$ data was used to calculate the $\gamma_{s}$ components by applying the Young's equation (Adamson and Gast, 1997):

$2 \sqrt{\gamma_{S}^{L W} \gamma_{L}^{L W}}+2 \sqrt{\gamma_{S}^{+} \gamma_{L}^{+}}+2 \sqrt{\gamma_{S} \gamma_{L}^{+}}=(1+\cos \theta) \gamma_{L}^{T O T}$

The value of the $\gamma_{s}^{L W}, \gamma_{s}^{-}$, and $\gamma_{s}^{+}$, components were $47.613 \pm 0.542 \mathrm{~mJ} / \mathrm{m}^{2}, 2.471 \pm 0.754 \mathrm{~mJ} / \mathrm{m}^{2}$, and $0.021 \pm 0.008 \mathrm{~mJ} / \mathrm{m}^{2}$, respectively. Hence, PZQ was found to be a monopolar electron-donor solid (van Oss, 2006): this anthelmintic agent can have acid-base interactions with phases of whatever polarity $\left(\gamma_{s}^{-}\right.$and $\gamma_{s}^{+}$different from zero), even though the acid-base forces do not contribute to its cohesion free energy.

These $\gamma_{s}$ components further manifest themselves in the hydrophobic/hydrophilic character of the drug particles, and they can be used to evaluate the free energy of interaction $\left(\Delta G_{\mathrm{SLS}}\right.$, not considering the electrostatic component) between the solid phases immersed in the liquid (van Oss, 2006). This quantity is written as follows per unit area of interacting particles:

$\Delta G_{S L S}=-2 \cdot \gamma_{S L}^{T O T}=-2 \cdot\left(\gamma_{S L}^{L W}+\gamma_{S L}^{A B}\right)=-2 \cdot\left(\gamma_{S L}^{L W}+2 \sqrt{\gamma_{S}^{+} \gamma_{S}^{-}}+2 \sqrt{\gamma_{S}^{-} \gamma_{S}^{+}}-2 \sqrt{\gamma_{S}^{+} \gamma_{L}^{-}}-2 \sqrt{\gamma_{S}^{-} \gamma_{L}^{+}}\right)$

The negative value of $\Delta G_{\text {SLS }}$ for the PZQ particles $\left(-78.37 \pm 5.48 \mathrm{~mJ} / \mathrm{m}^{2}\right)$ characterized the hydrophobic nature of the drug, this postulating that interfacial interactions will support attraction of the nanoparticles to each other in the aqueous media.

3.2. Effects of electrolyte type and concentration on the stability and redispersibility of PZQ aqueous nanosuspensions 
Introducing electrolytes in the composition of the dispersion medium has been described to help in the control of the electrical surface charge of pharmaceutical formulations based on colloids and suspensions (Arias et al. 2008, 2009; Cózar-Bernal et al., 2010; Gallardo et al., 2000, 2003). Thus, the significance of characterizing how the stability of the PZQ aqueous nanosuspension depended on the electrolyte type and concentration.

Figs. 1a, 2a, and 3a gather the sedimentation $(F \%)$ versus time curves of the PZQ aqueous nanosuspensions at their natural $\mathrm{pH}\left(\mathrm{pH}\right.$ 5), when $\mathrm{NaCl}, \mathrm{CaCl}_{2}$, and $\mathrm{AlCl}_{3}$ were incorporated in concentrations up to $10^{-1} \mathrm{M}$. Independently of the electrolyte type and concentration, the initial sediment volume was very low and progressively increased with time to get stable sediments after $\approx$ 60 h. Additionally, it was observed a small tendency toward greater flocculation ratios and faster settling rates as both the valence of the electrolyte and concentration increased. The hydrophobic character of the anthelmintic drug (see Section 3.1.), determining particle aggregation, could be behind the absence of more significant differences in the sedimentation profiles even at the very low electrolyte concentrations were the drug would tend to settle as individual particles (high zeta potential, $\zeta$, see below).

This behaviour was confirmed by the relative absorbance (optical absorbance $A$, relative to its initial value, $A_{0}$ ) versus time curves (Figs. $1 \mathrm{~b}, 2 \mathrm{~b}$, and $3 \mathrm{~b}$ ). The ratio $A / A_{0}$ decreased with time, as PZQ particles disappeared out of the light beam during sedimentation. Faster settling rates were characteristic of the slightly more voluminous (heavy) sediments probably generated at the greatest electrolyte concentrations.

These stability and redispersibility profiles could be qualitatively explained in the context of the DLVO classical theory of the stability of hydrophobic colloids (Hunter, 2001), by considering the evolution of the electric double layer properties of the PZQ nanoparticles when varying the electrolyte type and concentration (Fig. 4). Regarding the ionic strength, an increase may favour the accumulation of counterions closer to the drug surface, and hence a reduction in the electric double layer thickness. The resulting lower electrical potential in the shear plane defined low $|\zeta|$ values for 
the PZQ nanoparticles, and accordingly weak electrostatic repulsions between the drug particles that determine the fast sedimentation rates and the formation of voluminous sediments (Figs. 1, 2, and 3), which complete redispersion was slightly easier. As these repulsions were maximized when the electrolyte concentration was reduced, the opposite occurred for the high $|\zeta|$ values characteristic of the particles, and slow sedimentation of individual particles may be facilitated (Arias et al., 2009; Gallardo et al., 2000, 2003). The average particle-particle distance could thus be small, and particles will be at the range of van der Waals attractions, packing into compact sediments, difficult to redisperse.

With respect to the valence of the counterion, a similar effect was observed when it was increased. The highly charged counterion $\mathrm{Al}^{3+}$ was more efficient in reducing the $\zeta$ values than the divalent $\mathrm{Ca}^{2+}$ cation, which in turn was more efficient than $\mathrm{Na}^{+}$(Fig. 4), probably a consequence of the Schulze-Hardy rule (briefly described below). In fact, the $\zeta$ values were found to be positive almost within the range of concentrations investigated for the trivalent cation. As well, the very low $\zeta$ values generated even at weak ionic strengths for $\mathrm{AlCl}_{3}$ could explain the formation of slightly more voluminous aggregates, settling lightly faster (Fig. 3).

Given the incomplete coverage of the drug surface by counterions at low electrolyte concentrations, $\mathrm{Cl}^{-}$ions could reach the solid/liquid interface and an additional increase in the negative $\zeta$ could take place. This effect was compensated by the double-layer compression coming from increasing counterion concentrations. Adsorption of these co-ions may be prevented or reduced when the electrolyte concentration (number of cations) was increased. Thanks to the greater charge of $\mathrm{Al}^{3+}$, this cation was more efficient in this coating effect (strong interaction with the PZQ surface), and $\zeta$ data moved to positive values (Cózar-Bernal et al., 2010; Ruiz et al., 2004).

Finally, total redispersion was possible after $\approx 4$ and $\approx 1$ min of ultrasonic shaking of the nanosuspensions with small and high ionic strengths and/or valence of the counterion, respectively. In addition, it was observed the maintenance of the original mean particle size $(\approx 600 \mathrm{~nm})$ up to five months in the flocculated PZQ nanosuspensions (see Table 1). This probably meaning the absence 
of irreversible particle aggregation (generation of macroaggregates) under the standard storage conditions $\left(4.0 \pm 0.5^{\circ} \mathrm{C}\right)$.

\subsection{Effects of $p H$ on the stability and redispersibility of $P Z Q$ aqueous nanosuspensions}

The $\mathrm{pH}$ of the dispersion media has been classically described to display a significant effect on the electrical surface charge of many drugs (and polymers) of pharmaceutical interest (Arias et al. 2008, 2009; Cózar-Bernal et al., 2010; Ruiz et al., 2004). Therefore, it was relevant to analyse how the colloidal stability of the anthelmintic drug depended on $\left[\mathrm{H}^{+}\right]$.

Fig. 5a exemplifies the type of time evolution registered for the $F(\%)$ of the PZQ nanosuspensions at three $\mathrm{pH}$ values (sedimentation versus time curves). Generally speaking, $V_{0}$ was very low and progressively increased with time, so that $\approx 60 \mathrm{~h}$ were needed to get a constant low $V_{\mathrm{s}}$. It can be additionally identified in the figure a slight trend towards lower sedimentation values as the $\mathrm{pH}$ was increased. Again and as previously postulated in Section 3.2., the hydrophobic character of the PZQ particles (see Section 3.1.) could be behind the small differences found in the sedimentation profiles.

These results were verified by the relative absorbance versus time curves (Fig. 5b): the slight trend for lower sedimentation values as the $\mathrm{pH}$ increases (plotted in Fig. 5a) was confirmed, possibly a consequence of the lower weight of these lightly less voluminous flocculi.

These results could be qualitatively explained in the context of the DLVO classical theory of the stability of hydrophobic colloids (Hunter, 2001). As can be observed in Fig. 6, PZQ nanoparticles showed a well-defined isoelectric point $\left(\mathrm{pH}_{\mathrm{iep}}\right.$ or $\mathrm{pH}$ of zero $\zeta$ ) in the vicinity of $\mathrm{pH} 3.7$. As $\mathrm{pH}$ became more acidic, the decrease in $|\zeta|$ values could come from neutralization of the negative regions at the drug surface by adsorption of increasing quantities of $\mathrm{H}^{+}$ions (Arias et al. 2008, Cózar-Bernal et al., 2010; Ruiz et al., 2004). This dependence of the surface electrical charge of the solid with the $\mathrm{pH}$ of the dispersion media may explain the stability and redispersibility of the PZQ dispersions above described. At $\mathrm{pH} 3$, the low $\zeta$ values (and hydrophobic character) of the particles 
may favour aggregation of voluminous flocculi, also characterized by a large weight, by van der Waals attraction, and these aggregates generated visible sediments in a short period of time (fast sedimentation). Despite the hydrophobic attraction between the solids, the average distance between them could be slightly large and the nanosuspensions would be easily redispersible even by mild shaking. Concretely, complete redispersion of the sediments was possible after $\approx 1 \mathrm{~min}$ of ultrasonic shaking at acid $\mathrm{pHs}$.

On the contrary, at higher $\mathrm{pH}$ values (basic $\mathrm{pHs}$ ), electrostatic double layer repulsions between the drug particles should take place due to their larger electrokinetic potential (Fig, 6). The nanosuspension could now be considered colloidally stable, this determining lower $F(\%)$ values in Fig. 5a and the slightly higher $A / A_{0}$ values in Fig. 5b. PZQ solids are expected to settle as individual particles that will pack efficiently into a compact sediment, smaller than at acid pHs (despite the hydrophobic character of the drug), slightly difficult to redisperse (total redispersion after $\approx 4 \mathrm{~min}$ of ultrasonic shaking).

Finally, and similarly to what was described in Section 3.2., the original particle size was kept constant $(\approx 600 \mathrm{~nm})$ up to five months in the flocculated PZQ nanosuspensions (see Table 2 ), presumably meaning the absence of irreversible aggregation under the standard storage conditions $\left(4.0 \pm 0.5^{\circ} \mathrm{C}\right)$.

\section{Conclusions}

Stability (and redispersibility) of praziquantel nanosuspensions is essentially controlled by: $i$ ) the hydrophobic character of this anthelmintic drug; and, ii) the electrokinetics of the particles and the thickness of their ionic double layers. Although the former property intensely determines the flocculation curves, modification of $\mathrm{pH}$ and incorporation of electrolytes may contribute to the control of the stability of the colloids. The combined use of moderate or even low concentrations of $\mathrm{AlCl}_{3}$ and acidic $\mathrm{pHs}$ should allow the formulation of praziquantel aqueous nanosuspensions with very appropriate stability and redispersibility profiles for pharmaceutical applications. Formulation 
of this BCS Class II drug in the form of a nanosuspension could be a promising method to improve the poor solubility limiting its in vivo bioavailability due to a low dissolution rate in gastrointestinal fluids following oral administration. Additional preformulation studies are needed to include additional excipients in a final liquid PZQ dosage form, e.g. flavouring agents for enhancing patient acceptance (given the disgusting taste of pure drug and electrolytes), and polymers and surfactants (e.g. poloxamers, polyvinyl alcohol, polyvinylpyrrolidone, or sodium lauryl sulfate, to gain the benefits of a steric stabilization).

\section{Acknowledgements}

Financial support from Junta de Andalucía (Spain, project PE-2012-FQM-694).

\section{Declaration of interest}

The authors have no relevant affiliations or financial involvement with any organization or entity with a financial interest in or financial conflict with the subject matter or materials discussed in the manuscript. This includes employment, consultancies, honoraria, stock ownership or options, expert testimony, grants or patents received or pending, or royalties. 


\section{References}

Abrahamsson, B., Odman, J., 2008. Pharmaceutical Compositions. Patent US20080058399A1.

Adamson, A.W., Gast, A.P., 1997. Physical Chemistry of Surfaces, sixth ed. John Wiley \& Sons, Inc., New York.

Arias, J.L., López-Viota, M., Clares, B., Ruiz, M.A., 2008. Stability of fenbendazole suspensions for veterinary use. Correlation between zeta potential and sedimentation. Eur. J. Pharm. Sci. 34, 257-262. doi: 10.1016/j.ejps.2008.04.008.

Arias, J.L., Gómez-Gallo, A., Delgado, A.V., Gallardo, V., 2009. Study of the stability of Kollidon ${ }^{\circledR}$ SR suspensions for pharmaceutical applications. Colloids Surf. A: Physicochem. Eng. Aspects 338, 107-113. doi: 10.1016/j.colsurfa.2009.01.001.

Caffrey, C.R., 2007. Chemotherapy of schistosomiasis: present and future. Curr. Opin. Chem. Biol. 11, 433-439. doi: 10.1016/j.cbpa.2007.05.031.

Colley, D.G., Bustinduy, A.L., Secor, W.E., King, C.H., 2014. Human schistosomiasis. Lancet 383, 2253-2264. doi: 10.1016/S0140-6736(13)61949-2.

Conway, J., Bero, L., Ondari, C., Wasan, K.M., 2013. Review of the quality of pediatric medications in developing countries. J. Pharm. Sci. 102, 1419-1433. doi: 10.1002/jps.23474.

Cózar-Bernal, M.J., Gallardo, V., Sáez-Fernández, E., Holgado, M.A., Alvarez-Fuentes, J., Fernández-Arévalo, M., Arias, J.L., 2010. Role of the electrokinetic properties on the stability of mebendazole suspensions for veterinary applications. Int. J. Pharm. 393, 161-166. doi: 10.1016/j.ijpharm.2010.04.031.

Crompton, D.W., Nesheim, M.C., 2002. Nutritional impact of intestinal helminthiasis during the human life cycle. Annu. Rev. Nutr. 22, 35-59. doi: 10.1146/annurev.nutr.22.120501.134539.

Gallardo, V., Ruiz, M.A., Delgado, A.V., 2000. Pharmaceutical suspensions and their applications, in: Nielloud, F., Marti-Mestres, G. (Eds.), Pharmaceutical Emulsions and Suspensions, Marcel Dekker, New York, pp. 409-464. 
Gallardo, V., Ruiz, M.A., López-Viota, J., Salcedo, J., Delgado, A.V., 2003. Electrokinetic study of omeprazole drug in aqueous suspensions. Colloids Surf. A: Physicochem. Eng. Aspects 218, 2126. doi: 10.1016/S0927-7757(02)00589-7.

Hoppu, K., Sri Ranganathan, S., 2015. Essential medicines for children. Arch. Dis. Child. 100 Suppl 1, S38-S42. doi: 10.1136/archdischild-2013-305705.

Hotez, P., Aksoy, S., 2017. PLOS Neglected Tropical Diseases: ten years of progress in neglected tropical disease control and elimination... more or less. PLoS Negl. Trop. Dis. 11, e0005355. doi: 10.1371/journal.pntd.0005355.

Hotez, P.J., Brindley, P.J., Bethony, J.M., King, C.H., Pearce, E.J., Jacobson, J., 2008. Helminth infections: the great neglected tropical diseases. J. Clin. Invest. 118, 1311-1321. doi: 10.1172/JCI34261.

Hunter, R.J., 2001. Foundations of Colloid Science, second ed. Clarendon Press, Oxford.

King, C.H., Dickman, K., Tisch, D.J., 2005. Reassessment of the cost of chronic helmintic infection: a meta-analysis of disability-related outcomes in endemic schistosomiasis. Lancet 365, 1561-1569. doi: 10.1016/S0140-6736(05)66457-4.

Linderberg, M., Kopp, S., Dressman, J., 2004. Classification of orally administered drugs on the World Health Organization Model list of Essential Medicines according to the biopharmaceutics classification system. Eur. J. Pharm. Biopharm. 58, 265-278. doi: 10.1016/j.ejpb.2004.03.001.

Lustigman, S., Prichard, R.K., Gazzinelli, A., Grant, W.N., Boatin, B.A., McCarthy, J.S., Basáñez, M.G., 2012. A research agenda for helminth diseases of humans: the problem of helminthiases. PLoS Neg1. Trop. Dis. 6, e1582. doi: 10.1371/journal.pntd.0001582.

Malhado, M., Pinto, D.P., Silva, A.C., Silveira, G.P., Pereira, H.M., Santos, J.G. Jr., GuilarducciFerraz, C.V., Viçosa, A.L., Nele, M., Fonseca, L.B., Pinto, J.C., Calil-Elias, S., 2016. Preclinical pharmacokinetic evaluation of praziquantel loaded in poly (methyl methacrylate) nanoparticle using a HPLC-MS/MS. J. Pharm. Biomed. Anal. 117, 405-412. doi: 10.1016/j.jpba.2015.09.023. 
Matthews, B.A., Rhodes, C.T., 1970. Use of the Derjaguin, Landau Verwey and Overbeek theory to interpret pharmaceutical suspension stability. J. Pharm. Sci. 59, 521-526. doi: 10.1002/jps.2600590417.

Mourão, S.C., Costa, P.I., Salgado, H.R., Gremião, M.P., 2005. Improvement of antischistosomal activity of praziquantel by incorporation into phosphatidylcholine-containing liposomes. Int. J. Pharm. 295, 157-162. doi: 10.1016/j.ijpharm.2005.02.009.

Olveda, D.U., Li, Y., Olveda, R.M., Lam, A.K., Chau, T.N., Harn, D.A., Williams, G.M., Gray, D.J., Ross, A.G., 2013. Bilharzia: pathology, diagnosis, management and control. Trop. Med. Surg. 1, 135. doi: 10.4172/2329-9088.1000135.

Qian, M., Wei, L., Hao, L., Tang, S., 2017. Pharmacokinetics of new high-concentration and longacting praziquantel oily suspensions after intramuscular administration in cattle. J. Vet. Pharmacol. Ther. 40, 454-458. doi: 10.1111/jvp.12378.

Raso, G., Vounatsou, P., McManus, D.P., N'Goran, E.K., Utzinger, J., 2007. A Bayesian approach to estimate the age-specific prevalence of Schistosoma mansoni and implications for schistosomiasis control. Int. J. Parasitol. 37, 1491-500. doi: 10.1016/j.ijpara.2007.05.004.

Ross, A.G., Olds, G.R., Cripps, A.W., Farrar, J.J., McManus, D.P., 2013. Enteropathogens and chronic illness in returning travelers. N. Engl. J. Med. 368, 1817-1825. doi: 10.1056/NEJMra1207777.

Ruiz, M.A., Gallardo, V., Ouazzani, N., López-Viota, J., López-Durán, J.D., 2004. Electrophoretic properties of acrylic latex suspensions (Kollicoat MAE 30 D) and ibuprofen. Farmaco 59, 65762. doi: 10.1016/j.farmac.2004.03.007.

Steinmann, P., Keiser, J., Bos, R., Tanner, M., Utzinger, J., 2006. Schistosomiasis and water resources development: systematic review, meta-analysis, and estimates of people at risk. Lancet Infect. Dis. 6, 411-425. doi: 10.1016/S1473-3099(06)70521-7. 
Tang, S., Chen, L., Qian, M., Hao, L., Xiao, X., 2016. Pharmacokinetics of a new ivermectin/praziquantel suspension after intramuscular administration in sheep. Vet. Parasitol. 221, 54-58. doi: 10.1016/j.vetpar.2016.01.024.

Torabi, N., Dobakhti, F., Faghihzadeh, S., Haniloo, A., 2018. In vitro and in vivo effects of chitosan-praziquantel and chitosan-albendazole nanoparticles on Echinococcus granulosus Metacestodes. Parasitol. Res. 117, 2015-2023. doi: 10.1007/s00436-018-5849-z.

van Oss, C.J., 2006. Interfacial Forces in Aqueous Media, second ed. CRC Press, Boca Raton.

Viota, J.L., Lopez-Viota, M., Saake, B., Stana-Kleinschek, K., Delgado, A.V., 2010. Organoclay particles as reinforcing agents in polysaccharide films. J. Colloid Interface Sci. 347, 74-78. doi: 10.1016/j.jcis.2010.03.009.

Xie, S., Pan, B., Shi, B., Zhang, Z., Zhang, X., Wang, M., Zhou, W., 2011. Solid lipid nanoparticle suspension enhanced the therapeutic efficacy of praziquantel against tapeworm. Int. J. Nanomedicine 6, 2367-2374. doi: 10.2147/IJN.S24919. 


\section{Figure Captions}
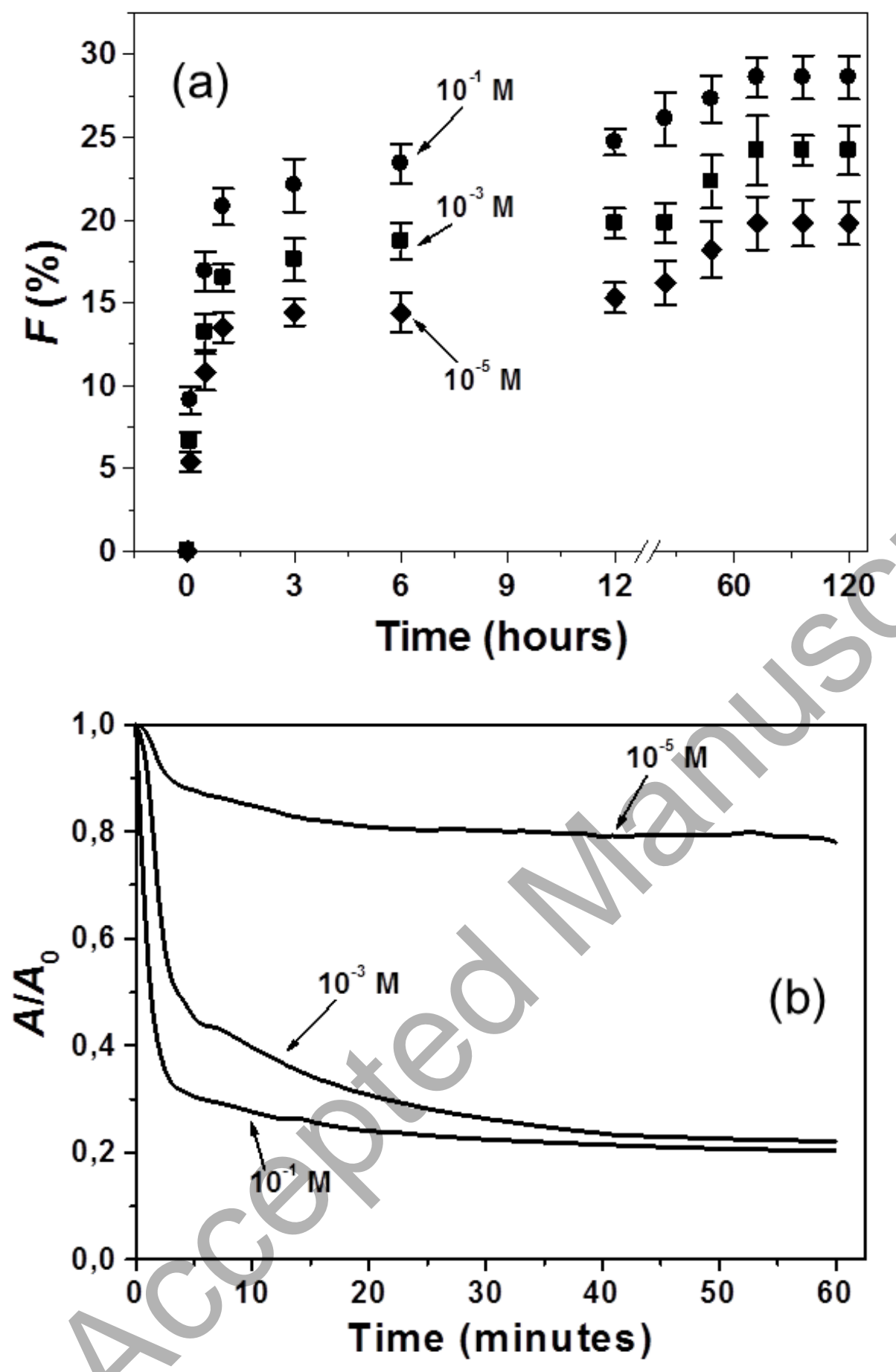

Figure 1. Flocculation ratio $\left(F, V_{\mathrm{s}} / V_{0}, \%\right)(a)$, and $(b)$ optical absorbance $A$ (relative to its initial value, $\left.A_{0}\right)$, as a function of time for PZQ aqueous dispersions $(\mathrm{pH}$ 5) at the $\mathrm{NaCl}$ molar concentrations: $10^{-1}(\bullet), 10^{-3}(\mathbf{\bullet})$, and $10^{-5}(\bullet)$. 

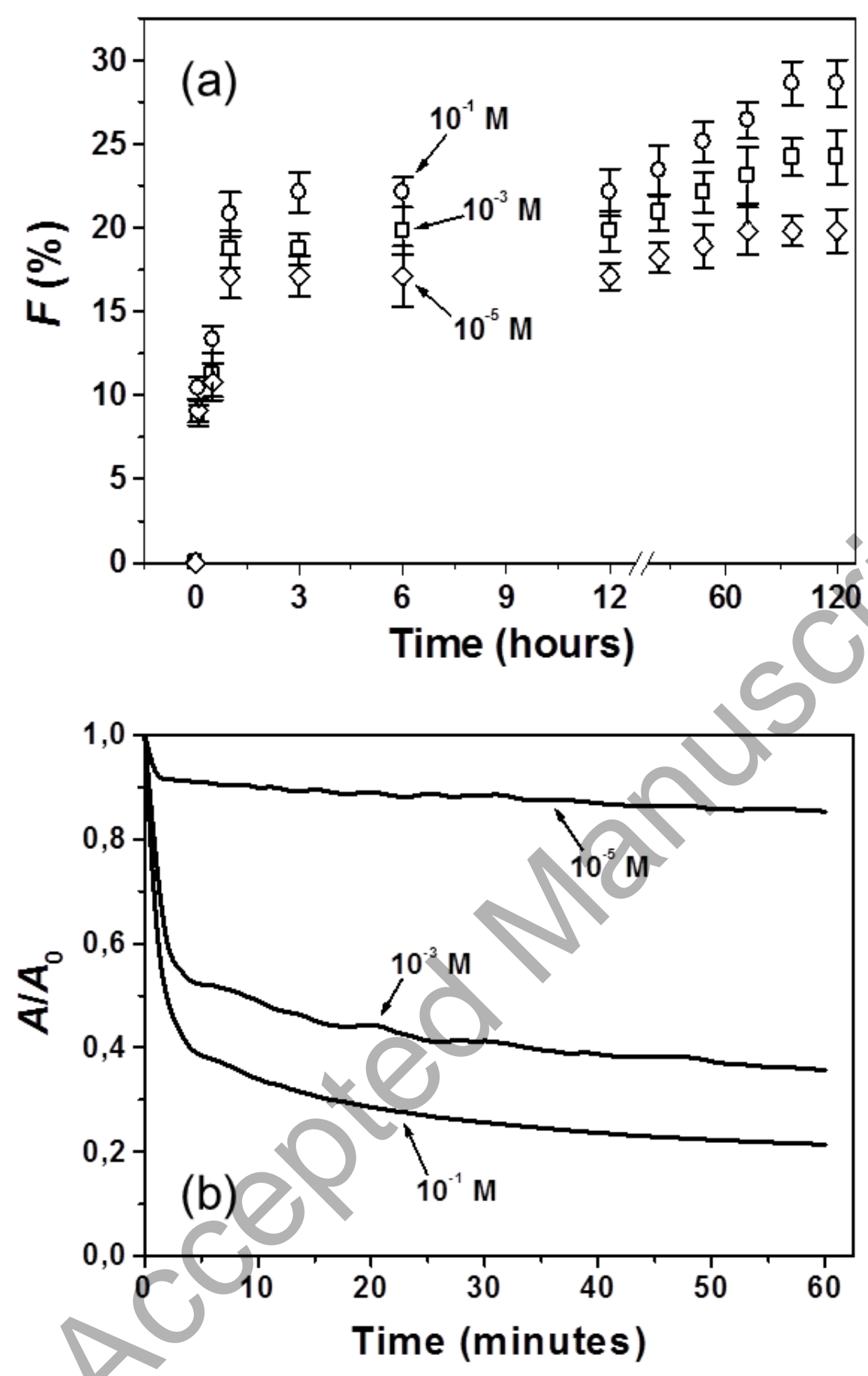

Figure 2. Flocculation ratio $\left(F, V_{\mathrm{s}} / V_{0}, \%\right)(a)$, and $(b)$ optical absorbance $A$ (relative to its initial value, $A_{0}$ ), as a function of time for $\mathrm{PZQ}$ aqueous dispersions $\left(\mathrm{pH}\right.$ 5) at the $\mathrm{CaCl}_{2}$ molar concentrations: $10^{-1}(\circ), 10^{-3}(\square)$, and $10^{-5}(\diamond)$. 

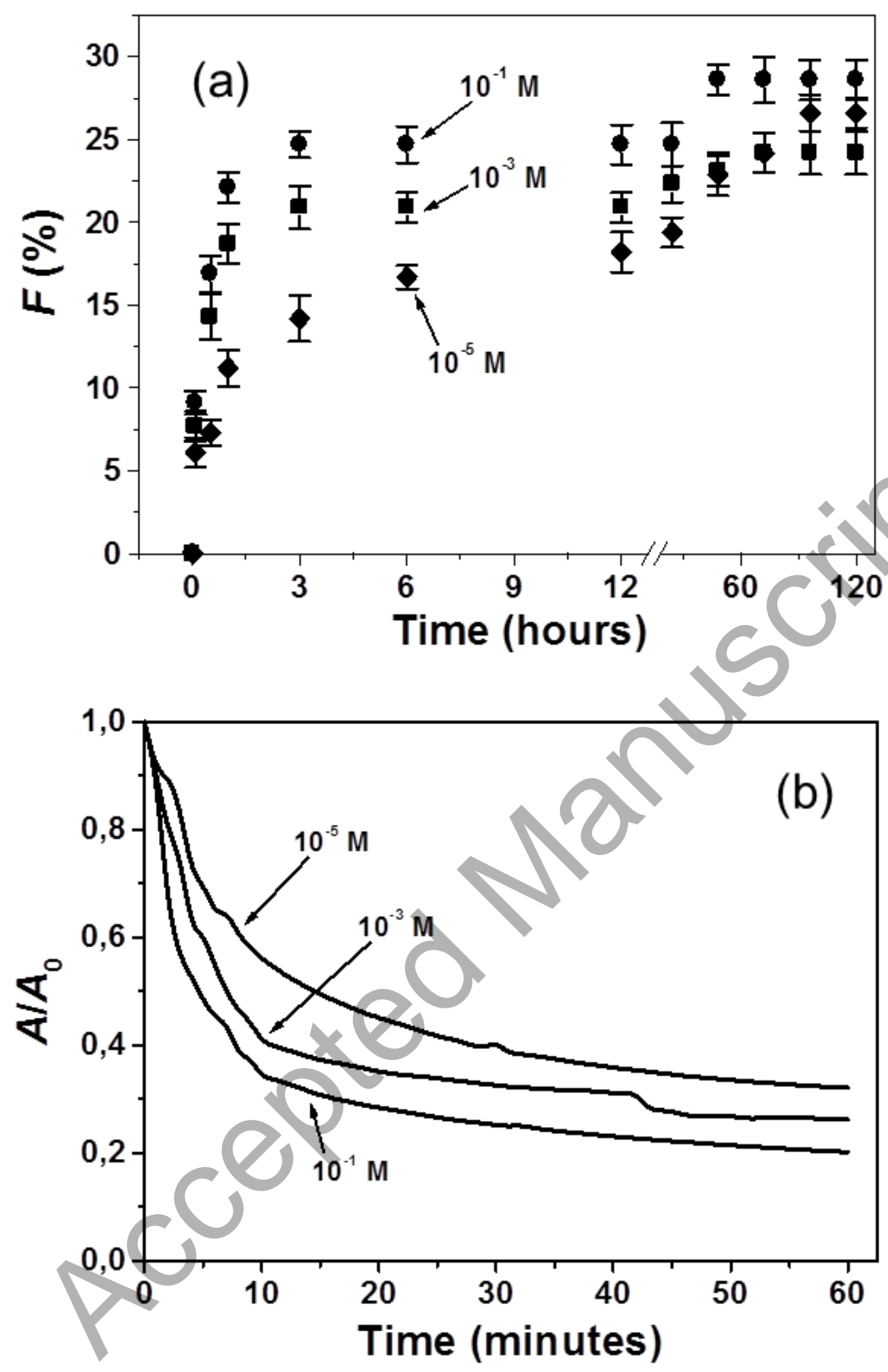

Figure 3. Flocculation ratio $\left(F, V_{\mathrm{S}} / V_{0}, \%\right)(a)$, and $(b)$ optical absorbance $A$ (relative to its initial value, $\left.A_{0}\right)$, as a function of time for PZQ aqueous dispersions $\left(\mathrm{pH}\right.$ 5) at the $\mathrm{AlCl}_{3}$ molar concentrations: $10^{-1}(\bullet), 10^{-3}(\mathbf{\bullet})$, and $10^{-5}(\bullet)$. 


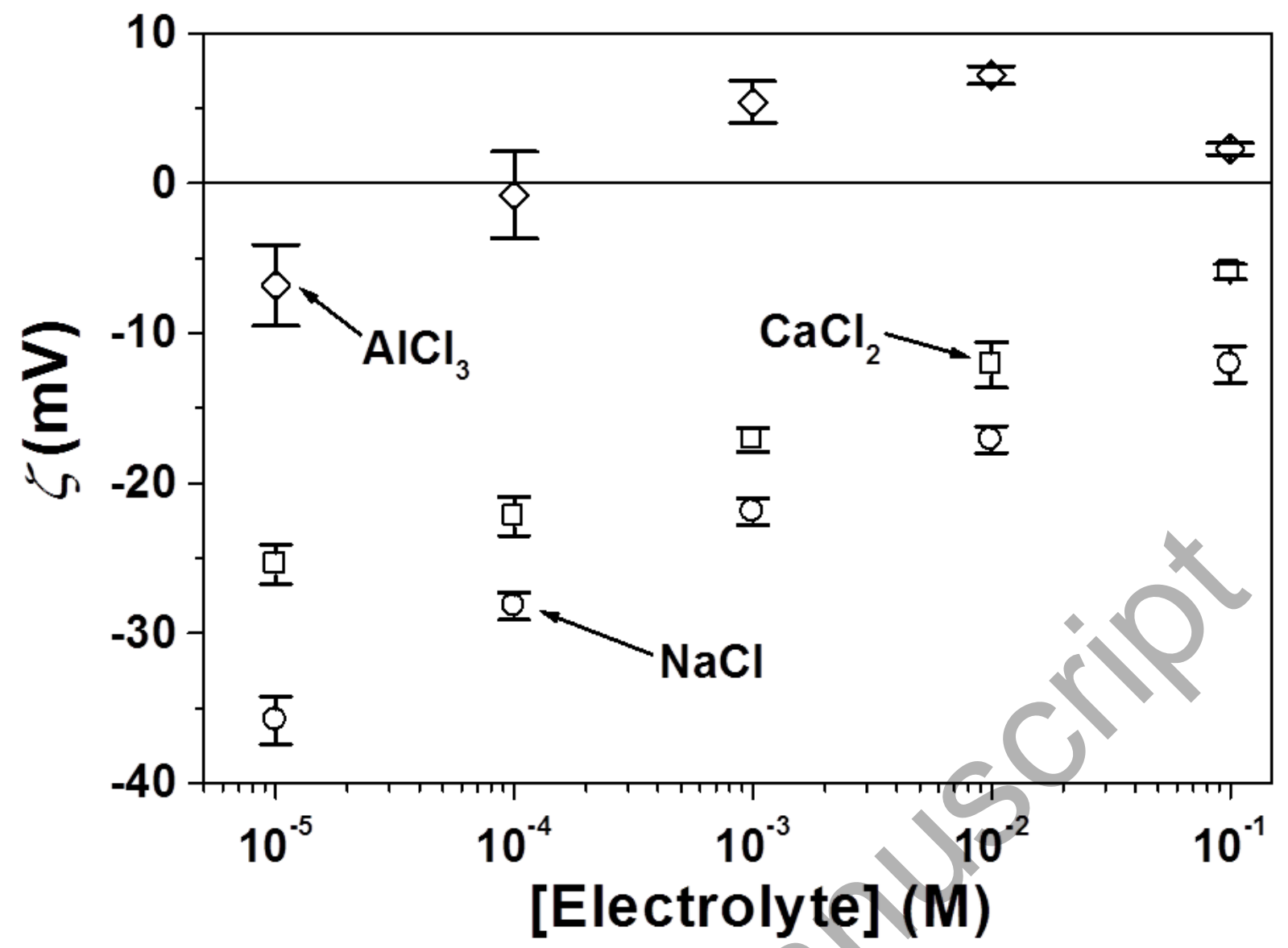

Figure 4. Zeta potential $(\zeta, \mathrm{mV})$ of PZQ nanoparticles as a function of the concentration of $\mathrm{NaCl}$ $(\odot), \mathrm{CaCl}_{2}(\square)$ and $\mathrm{AlCl}_{3}(\diamond)$ at $\mathrm{pH} 5$. 

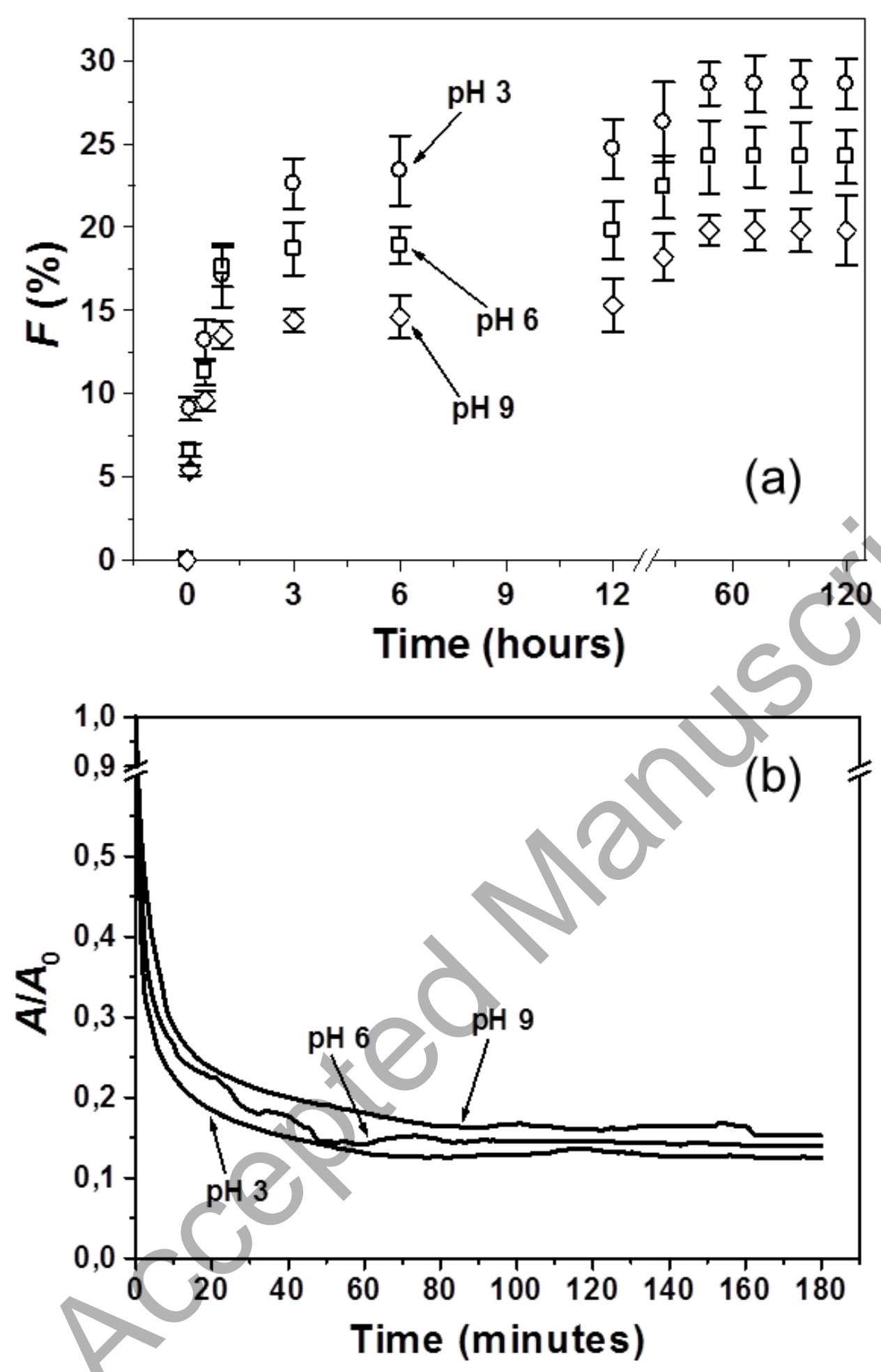

Figure 5. Flocculation ratio $\left(F, V_{\mathrm{s}} / V_{0}, \%\right)(a)$, and $(b)$ optical absorbance $A$ (relative to its initial value, $\left.A_{0}\right)$, as a function of time for PZQ aqueous dispersions at $\mathrm{pH} 3(\circ), 6(\square)$, and $9(\diamond)$, in the presence of $10^{-3} \mathrm{M} \mathrm{NaCl}$. 


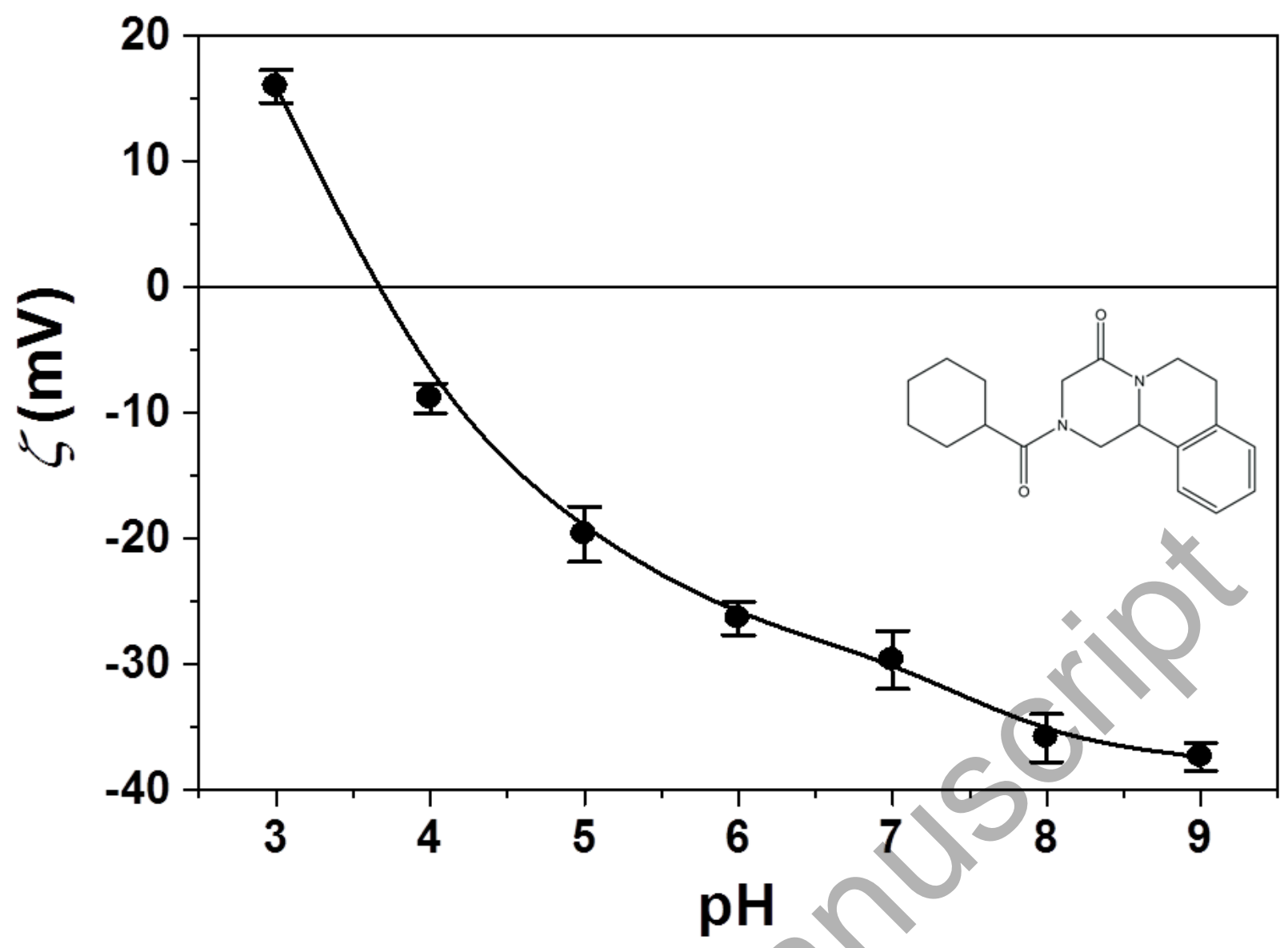

Figure 6. Zeta potential $(\zeta, \mathrm{mV})$ of PZQ nanoparticles as a function of $\mathrm{pH}$ in the presence of $10^{-3}$ $\mathrm{M} \mathrm{NaCl}$. Inset: chemical structure of this anthelmintic drug. 
Table 1. Effects of electrolyte type and concentration on the redispersibility of $P Z Q$ aqueous nanosuspensions stored under standard conditions ( $4.0 \pm 0.5 \stackrel{\circ}{ })$ : aspect on visual inspection, and evolution with time of the particle size. The values are the mean \pm standard deviation (SD) of triplicate experiments.

\begin{tabular}{|c|c|c|c|c|c|c|}
\hline \multirow{2}{*}{$\begin{array}{c}\text { Electrolyte type and } \\
\text { concentration }\end{array}$} & \multicolumn{6}{|c|}{ Size (nm) } \\
\hline & Month 1 & Month 2 & Month 3 & Month 4 & Month 5 & Month 6 \\
\hline $10^{-5} \mathrm{M} \mathrm{NaCl}$ & $\begin{array}{c}\text { Macroaggr } \\
\text { egates }\end{array}$ & $\begin{array}{c}\text { Macroaggr } \\
\text { egates }\end{array}$ & $\begin{array}{c}\text { Macroaggr } \\
\text { egates }\end{array}$ & $\begin{array}{c}\text { Macroaggr } \\
\text { egates }\end{array}$ & $\begin{array}{l}\text { Macroaggr } \\
\text { egates }\end{array}$ & $\begin{array}{c}\text { Macroaggr } \\
\text { egates }\end{array}$ \\
\hline $10^{-5} \mathrm{M} \mathrm{CaCl}_{2}$ & $\begin{array}{c}930 \pm 140 \\
\text { (complete } \\
\text { redispersio } \\
\text { n, } \\
\text { homogene } \\
\text { ous aspect) }\end{array}$ & $\begin{array}{c}\text { Macroaggr } \\
\text { egates }\end{array}$ & $\begin{array}{c}\text { Macroaggr } \\
\text { egates }\end{array}$ & $\begin{array}{c}\text { Macroaggr } \\
\text { egates }\end{array}$ & $\begin{array}{l}\text { Macroaggr } \\
\text { egates }\end{array}$ & $\begin{array}{c}\text { Macroaggr } \\
\text { egates }\end{array}$ \\
\hline $10^{-5} \mathrm{M} \mathrm{AlCl}_{3}$ & $\begin{array}{c}630 \pm 80 \\
\text { (complete } \\
\text { redispersio } \\
\text { n, } \\
\text { homogene } \\
\text { ous aspect) }\end{array}$ & $\begin{array}{c}670 \pm 70 \\
\text { (complete } \\
\text { redispersio } \\
\text { n, } \\
\text { homogene } \\
\text { ous aspect) }\end{array}$ & $\begin{array}{c}640 \pm 60 \\
\text { (complete } \\
\text { redispersio } \\
n, \\
\text { homogene } \\
\text { ous aspect) }\end{array}$ & $\begin{array}{l}610 \pm 60 \\
\text { (complete } \\
\text { redispersio } \\
n, \\
\text { homogene } \\
\text { ous aspect) }\end{array}$ & $\begin{array}{c}750 \pm 120 \\
\text { (complete } \\
\text { redispersio } \\
\text { n, } \\
\text { homogene } \\
\text { ous aspect) }\end{array}$ & $\begin{array}{c}\text { Macroaggr } \\
\text { egates }\end{array}$ \\
\hline
\end{tabular}


Table 2. Effects of $\mathrm{pH}$ on the redispersibility of $\mathrm{PZQ}$ aqueous nanosuspensions stored under standard conditions $(4.0 \pm 0.5 \stackrel{\circ}{\circ})$ : aspect on visual inspection, and evolution with time of the particle size. The values are the mean \pm standard deviation (SD) of triplicate experiments.

\begin{tabular}{|c|c|c|c|c|c|c|}
\hline \multirow{2}{*}{$\mathrm{pH}$} & \multicolumn{6}{|c|}{ Size (nm) } \\
\hline & Month 1 & Month 2 & Month 3 & Month 4 & Month 5 & Month 6 \\
\hline 3 & $\begin{array}{c}600 \pm 60 \\
\text { (complete } \\
\text { redispersion, } \\
\text { homogeneous } \\
\text { aspect) }\end{array}$ & $\begin{array}{c}630 \pm 90 \\
\text { (complete } \\
\text { redispersion, } \\
\text { homogeneous } \\
\text { aspect) }\end{array}$ & $\begin{array}{l}620 \pm 80 \\
\text { (complete } \\
\text { redispersion, } \\
\text { homogeneous } \\
\text { aspect) }\end{array}$ & $\begin{array}{c}710 \pm 90 \\
\text { (complete } \\
\text { redispersion, } \\
\text { homogeneous } \\
\text { aspect) }\end{array}$ & $\begin{array}{c}790 \pm 110 \\
\text { (complete } \\
\text { redispersion, } \\
\text { homogeneous } \\
\text { aspect) }\end{array}$ & Macroaggrega \\
\hline 6 & $\begin{array}{c}880 \pm 160 \\
\text { (complete } \\
\text { redispersion, } \\
\text { homogeneous } \\
\text { aspect) }\end{array}$ & $\begin{array}{c}\text { Macroaggrega } \\
\text { tes }\end{array}$ & $\begin{array}{c}\text { Macroaggrega } \\
\text { tes }\end{array}$ & $\begin{array}{c}\text { Macroaggrega } \\
\text { tes }\end{array}$ & Macroaggr & $\begin{array}{c}\text { Macroaggrega } \\
\text { tes }\end{array}$ \\
\hline 9 & $\begin{array}{c}\text { Macroaggrega } \\
\text { tes }\end{array}$ & $\begin{array}{c}\text { Macroaggrega } \\
\text { tes }\end{array}$ & $\begin{array}{c}\text { Macroaggrega } \\
\text { tes }\end{array}$ & Macroaggrega & $\begin{array}{c}\text { Macroaggrega } \\
\text { tes }\end{array}$ & $\begin{array}{c}\text { Macroaggrega } \\
\text { tes }\end{array}$ \\
\hline
\end{tabular}




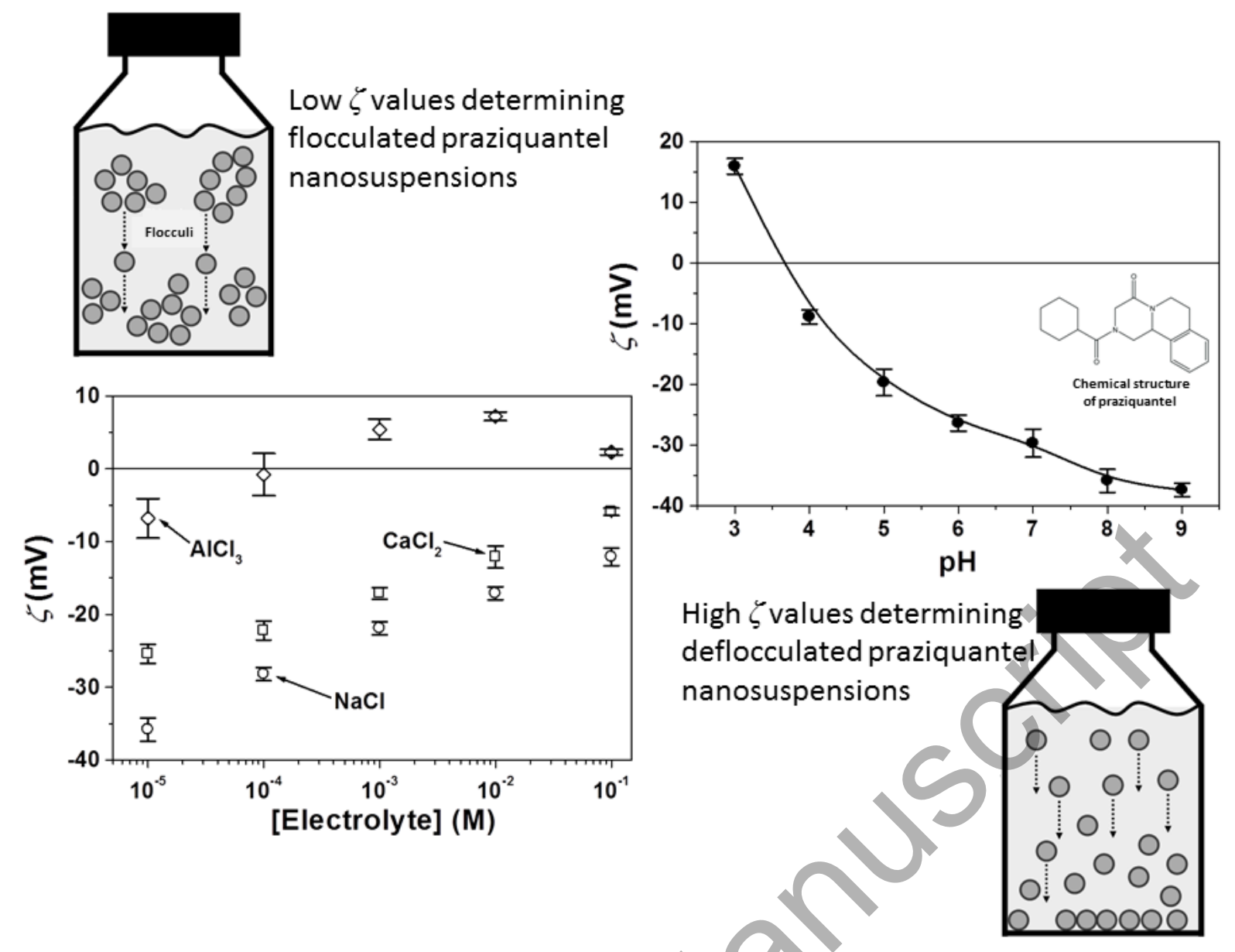

